\title{
Effect of Rosmarinus officinalis and Ocimum basilicum Extract on Peroxide Value, Carbonyl Compound, and Free Fatty Acids of Fish Oil
}

\author{
Maryam Asnaashari* ${ }^{1}$, Reza Farahmandfar $*^{2}$ and Reza Esmaeilzadeh Kenari ${ }^{3}$
}

\begin{abstract}
One of the newest attended techniques is ultrasound-assisted extraction. This method is more efficient and economic than solvent and ultrasound apart from. The purpose of the present work was evaluated and compare Rosmarinus officinalis and Ocimum basilicum extraction on the quality of fish oil in similar conditions. Results of chemical tests (peroxide value, carbonyl compound, and free fatty acids) showed that both of extracts could increase the storage period of Hypophthalmichtys molitrix fish oil. They delayed production of undesirable metabolites in samples and Rosmarinus officinalis extract was better than Ocimum basilicum one. In agreement, higher concentrations of both extracts were better than lower ones. There were significant differences between control and treated samples. This technique could be replaced for extraction from different sources.
\end{abstract}

Index Terms - Ocimum basilicum extract, Fish oil, Rosmarinus officinalis extract, Shelf life, Ultrasound-assisted solvent.

\section{INTRODUCTION}

Demanding for fish products is high because they are nutritious, safe, various and attractive in appearance and texture $[1,2]$. Fish oil are more vulnerable to spoilage than other edible oils as it contains relatively large amounts of unsaturated free fatty acids [3]. The quality of fish oil and seafood products degrades during storage due to a complex process such as physical, chemical, and microbiological mechanisms. Enzymatic and chemical reactions are usually responsible for the initial loss of freshness, whereas microbial activity is responsible for subsequent spoilage, which determines shelf life of product [4]. Chemical preservatives are often used to delay of deterioration. Due to possible toxicological side effects of these compounds on human health, the general trend toward using biopreservatives $[5,6]$. The antioxidant activity of plant extracts has been proved for many years and their dominant compounds recently have been applied in several foods especially edible oils [7-10].

The extracts of Rosemary (Rosmarinus officinalis) are widely used in pharmaceutical, cosmetic and perfume industry, and for

Reza Farahmandfar, Assistant Professor, Department of Food Science and Technology, Sari Agricultural Sciences \& Natural Resources University (SANRU), Sari, Iran.

Maryam Asnaashari, Department of Food Science and Technology, Sari Agricultural Sciences \& Natural Resources University (SANRU), Sari, Iran

Reza Esmaeilzadeh Kenari, Department of Food Science and Technology, Sari Agricultural Sciences \& Natural Resources University (SANRU), Sari, Iran. flavoring and preservation of several food products [11]. Phenolic compounds such as carnosol, carnosoic acid, rosmanol, rosmadial, epirosmanol, rosmadiphenol, rosmarinic acid, etc. are considered to have antioxidant ability [12].

Essential oils and extracts of Basil (Ocimum basilicum) are widely used because they have complex compositions, containing constituents of mostly hydrocarbons and oxygenated compounds [13]. It has a long history as culinary herb, thanks to its foliage adding a distinctive flavor to many foods. It is also a source of aroma compounds and essential oils containing biologically active constituents that possess insecticidal, nematicidal, fungistatic and antimicrobial properties [14].

At present, ultrasonic assisted extraction (UAE) is mainly used to obtain lipophilic and hydrophilic plant extracts. They are characterized by a different composition from those obtained through conventional extraction or distillation [15]. It has also been established that UAE is more effective than classical maceration (shorter time, larger output of volatile constituent extraction) [16]. UAE allows extraction at a lower temperature of the process, which is significant for raw materials that easily degrade [17].

The aim of this study was to use of ultrasound-assisted solvent for extraction of Rosmarinus officinalis and Ocimum basilicum and investigation the effect of these natural extracts on quality properties of Hypophthalmichtys molitrix fish oil after $0,4,8,12$ and 16 days' storage at $60^{\circ} \mathrm{C}$.

\section{MATERIALS AND MethodS}

\section{A. Materials}

Rosmarinus officinalis and Ocimum basilicum leaves were collected from north of Iran in Mazandaran province. Samples were dried in oven (Behdad, Iran) at $65^{\circ} \mathrm{C}$ for $24 \mathrm{~h}$ and powdered by mixer (Panasonic, MK-G20NR). Hypophthalmichtys molitrix fish oil was purchased from Khazar Company (Babolsar, Iran). All chemical reagents used for experiments were analytical grade.

\section{B. Extraction}

Crushed dried Rosmarinus officinalis and Ocimum basilicum leaves were added to appropriate ethanol $(1: 10 \mathrm{w} / \mathrm{v})$. The mixtures were extracted in a shaking water bath for $30 \mathrm{~min}$ at $45^{\circ} \mathrm{C}$. Crude extracts were sonicated with an ultrasonic probe system (Branson, 8510R-Mt, Canada) at $30 \mathrm{kHz}$ and $40 \mathrm{kHz}$ for $15 \mathrm{~min}$ at $40{ }^{\circ} \mathrm{C}$ for Rosmarinus officinalis and Ocimum 
basilicum, respectively. The extracts were filtered through Whatman No.1. The organic solvents were concentrated to near dryness using rotary evaporator bath (Buchi EL 141, Switzerland) under reduced pressure [18].

\section{Sample Preparation}

Hypophthalmichtys molitrix fish oil (5 g) containing 200 and $800 \mathrm{ppm}$ of Rosmarinus officinalis and Ocimum basilicum extracts were stored in a 1-mm layer in a Petri dish with a diameter of $9 \mathrm{~cm}$ at $60^{\circ} \mathrm{C}$. Progress of lipid oxidation was monitored primary and secondary oxidation parameters during storage time.

\section{Peroxide value (PV)}

The PV of fish oil samples containing different concentrations of Rosmarinus officinalis and Ocimum basilicum extracts were measured spectrophotometrically at $500 \mathrm{~nm}$ by UV-VIS instrument (GBC, Cintra 20). The oil samples were mixed in with $9.8 \mathrm{~mL}$ chloroform-methanol (7:3 $\mathrm{v} / \mathrm{v}$ ) on a vortex mixer for 2-4 s. Ammonium thiocyanate solution $(50 \mathrm{~mL}, 30 \% \mathrm{w} / \mathrm{v})$ and $50 \mathrm{~mL}$ of iron (II) chloride solution ([0.4 gr barium chloride dihydrate dissolved in $50 \mathrm{~mL}$ $\mathrm{H} 2 \mathrm{O}]+[0.5 \mathrm{gr} \mathrm{FeSO} 4.7 \mathrm{H} 2 \mathrm{O}$ dissolved in $50 \mathrm{~mL} \mathrm{H} 2 \mathrm{O}]+2 \mathrm{~mL}$ $10 \mathrm{M} \mathrm{HCl}$, with the precipitate, barium sulphate, filtered off to produce a clear solution]) were added, respectively and after adding each of them, the sample was mixed on a vortex mixer for 2-4 s. Then, the absorbance of the sample was read, after 5 min incubation at room temperature. Results were expressed in milliequivalents of oxygen per kilogram of oil.

\section{E. Carbonyl compound determination}

The CV of the fish oil sample was determined according to the method developed by [19] using 2-propanol and 2,4-decadienal as solvent and standard, respectively. To eliminate any carbonyl components, $1 \mathrm{~kg}$ of 2-propanol with 0.5 $\mathrm{g}$ of sodium borohydride was refluxed for $1 \mathrm{~h}$, then, $50 \mathrm{~g}$ of 2,4-dimitrophenylhydrazine (DNPH) were dissolved in $100 \mathrm{ml}$ of the solvent containing $3.5 \mathrm{ml}$ of $37 \% \mathrm{HCL}$. Approximately, $0.04-1.0 \mathrm{~g}$ of corn oil sample was put into a $10-\mathrm{mL}$ volumetric flask, and the flask was filled to volume with triphenylphosphine $(0.4 \mathrm{mg} / \mathrm{mL})$ to reach $10 \mathrm{~mL}$ to reduce hydroperoxide formation; then, standard carbonyl compound solution or oil solution $(1 \mathrm{~mL})$ and DNPH solution $(1 \mathrm{~mL})$ were mixed in a tube. After that, the tube was heated $\left(20 \mathrm{~min}, 40^{\circ} \mathrm{C}\right)$ and cooled in the water bath after adding $2 \% \mathrm{KOH}(8 \mathrm{~mL})$. The test tube was centrifuged (at $2000 \times \mathrm{g}$ for $5 \mathrm{~min}$ ) at room temperature. At the end, the absorbance of the upper layer was measured at $420 \mathrm{~nm}$.

\section{F. Free fatty acids (FFAs) determination}

The FFAs was determined according to the AOCS (1993) Official Method Cd 3d-63. In this method, $15 \pm 0.01 \mathrm{gr}$ of each fish oil samples were placed into a $250 \mathrm{~mL}$ Erlenmeyer flask and dissolved in $70 \mathrm{~mL}$ reagent grade alcohol containing phenolphthalein indicator and then each oil solution was subsequently titrated with the potassium hydroxide solution.

\section{G. Statistical analysis}

The obtained data were subjected to one-way analysis of variance using SPSS statistical software, release 18.0. Duncan's new multiple range test was performed to determine the significant differences of the means at the $5 \%$ probability level $(\mathrm{P}<0.05)$.

\section{RESULTS AND DISCUSSION}

PV values in treated and control samples of Hypophthalmichtys molitrix fish oil are shown in Table 1. The initial PV value in all samples at the beginning of storage period was $0.92-0.79 \mathrm{meq} \mathrm{O}_{2} / \mathrm{kg}$. PV values after 16 days of storage period were $8.13,5.44,5.01,4.23$ and 4.79 meq $\mathrm{O}_{2} / \mathrm{kg}$ for control, $200 \mathrm{ppm}$ (Rosmarinus officinalis and Ocimum basilicum) and $800 \mathrm{ppm}$ (Rosmarinus officinalis and Ocimum basilicum), respectively. Significant lower PV value was observed for treated samples during the storage period at $60^{\circ} \mathrm{C}$ $(P<0.05)$. However, there was not any significant difference between Rosmarinus officinalis and Ocimum basilicum UAM extracts. The PV value is an index of lipid oxidation measuring primary oxidation products. Fish oil are very susceptible to chemical deteriorations, due to their chemical composition [20]. Degradation of products formed during oxidation of unsaturated fatty acids is followed by the formation of low-molecular-weight volatile compounds, which accounts for foreign shades of odor and flavor [21]. The major protective effect of UAM Rosmarinus officinalis and Ocimum basilicum extracts are owed to its phenolic compounds [3].

TABLE I. CHANGES IN PV VALUE IN CONTROL AND TWO CONCENTRATIONS OF ROSMARINUS OFFICINALIS AND OCIMUM BASILICUM UAM IN

HYPOPHTHALMICHTYS MOLITRIX FISH OIL DURING STORAGE AT $60^{\circ} \mathrm{C}$

\begin{tabular}{llllll}
\hline \multirow{2}{*}{ Time(day) } & Control & $\mathbf{2 0 0} \mathbf{~ p p m}$ & \multicolumn{3}{c}{$\mathbf{8 0 0} \mathbf{~ p p m}$} \\
\cline { 2 - 5 } & & $\begin{array}{l}\text { Rosmarinus } \\
\text { officinalis }\end{array}$ & $\begin{array}{l}\text { Ocimum } \\
\text { basilicum }\end{array}$ & $\begin{array}{l}\text { Rosmarinus } \\
\text { officinalis }\end{array}$ & $\begin{array}{l}\text { Ocimum } \\
\text { basilicum }\end{array}$ \\
\hline zero & $0.92 \pm 0.04^{\mathrm{aE}}$ & $0.82 \pm 0.07^{\mathrm{bE}}$ & $0.88 \pm 0.02^{\mathrm{aE}}$ & $0.84 \pm 0.00^{\mathrm{bE}}$ & $0.79 \pm 0.01^{\mathrm{cE}}$ \\
$\mathbf{4}$ & $3.54 \pm 0.02^{\mathrm{aD}}$ & $2.11 \pm 0.01^{\mathrm{eD}}$ & $2.42 \pm 0.03^{\mathrm{bD}}$ & $2.17 \pm 0.02^{\mathrm{dD}}$ & $2.22 \pm 0.03^{\mathrm{cD}}$ \\
$\mathbf{8}$ & $5.74 \pm 0.04^{\mathrm{aC}}$ & $3.14 \pm 0.09^{\mathrm{dC}}$ & $3.84 \pm 0.02^{\mathrm{bC}}$ & $2.93 \pm 0.04^{\mathrm{eC}}$ & $3.45 \pm 0.06^{\mathrm{cC}}$ \\
$\mathbf{1 2}$ & $6.76 \pm 0.06^{\mathrm{aB}}$ & $4.31 \pm 0.05^{\mathrm{cB}}$ & $4.87 \pm 0.07^{\mathrm{bB}}$ & $3.84 \pm 0.02^{\mathrm{eB}}$ & $4.14 \pm 0.07^{\mathrm{dB}}$ \\
$\mathbf{1 6}$ & $8.13 \pm 0.02^{\mathrm{aA}}$ & $5.44 \pm 0.01^{\mathrm{bA}}$ & $5.01 \pm 0.01^{\mathrm{cA}}$ & $4.23 \pm 0.04^{\mathrm{eA}}$ & $4.79 \pm 0.02^{\mathrm{dA}}$ \\
\hline
\end{tabular}

Means with the same small and capital letters in a raw and column were not significantly different at $\mathrm{P}<0.05$ level in various treatments

Carbonyl value is a common indicator for the assessment of degree of lipid oxidation [22]. Carbonyl value in treated and control samples of Hypophthalmichtys molitrix fish oil are shown in Table 2. The initial carbonyl value in all samples at first was $0.75-0.59 \mathrm{mg}$ of malonaldehyde/ $\mathrm{kg}$ fat. Carbonyl value increased with time of storage at $60^{\circ} \mathrm{C}$ for all treatments and reached to 5.65, 3.92, 4.55, 3.05 and 3.85 for control, 200 ppm (Rosmarinus officinalis and Ocimum basilicum) and 800 ppm (Rosmarinus officinalis and Ocimum basilicum), respectively. Significant lower of carbonyl value was observed for treated samples and $800 \mathrm{ppm}$ of Rosmarinus officinalis and Ocimum basilicum extracts during the storage period at $60^{\circ} \mathrm{C}$ $(P<0.05)$. Carbonyl values of control and $800 \mathrm{ppm}$ samples reached to the Maximal recommended limit [23] for carbonyl values of fish (2 mg of malonaldehyde/ $\mathrm{kg}$ of fat) at day 8 of storage, while for $800 \mathrm{ppm}$ treatment, TBA content was still lower than upper acceptability limit. 
TABLE II. CHANGES IN CARBONYL VALUE IN CONTROL AND TWO CONCENTRATIONS OF ROSMARINUS OFFICINALIS AND OCIMUM BASILICUM UAM IN HYPOPHTHALMICHTYS MOLITRIX FISH OIL DURING STORAGE AT $60^{\circ} \mathrm{C}$

\begin{tabular}{llllll}
\hline \multirow{2}{*}{ Time(day) } & control & $\mathbf{2 0 0} \mathbf{~ p p m}$ & \multicolumn{3}{c}{$\mathbf{8 0 0} \mathbf{~ p p m}$} \\
\cline { 3 - 6 } & & $\begin{array}{l}\text { Rosmarinus } \\
\text { officinalis }\end{array}$ & $\begin{array}{l}\text { Ocimum } \\
\text { basilicum }\end{array}$ & $\begin{array}{l}\text { Rosmarinus } \\
\text { officinalis }\end{array}$ & $\begin{array}{l}\text { Ocimum } \\
\text { basilicum }\end{array}$ \\
\hline Zero & $0.75 \pm 0.02^{\mathrm{aE}}$ & $0.67 \pm 0.05^{\mathrm{bE}}$ & $0.60 \pm 0.02^{\mathrm{CE}}$ & $0.59 \pm 0.03^{\mathrm{CE}}$ & $0.63 \pm 0.06^{\mathrm{bE}}$ \\
$\mathbf{4}$ & $2.95 \pm 0.05^{\mathrm{aD}}$ & $1.33 \pm 0.02^{\mathrm{CD}}$ & $1.47 \pm 0.02^{\mathrm{bD}}$ & $1.25 \pm 0.04^{\mathrm{dD}}$ & $1.27 \pm 0.05^{\mathrm{dD}}$ \\
$\mathbf{8}$ & $3.75 \pm 0.12^{\mathrm{aC}}$ & $2.28 \pm 0.01^{\mathrm{cC}}$ & $2.48 \pm 0.07^{\mathrm{bC}}$ & $1.74 \pm 0.01^{\mathrm{eC}}$ & $2.2 \pm 0.04^{\mathrm{dC}}$ \\
$\mathbf{1 2}$ & $4.15 \pm 0.07^{\mathrm{aB}}$ & $3.26 \pm 0.02^{\mathrm{cB}}$ & $3.43 \pm 0.05^{\mathrm{bB}}$ & $2.89 \pm 0.09^{\mathrm{dB}}$ & $3.01 \pm 0.06^{6^{\mathrm{BB}}}$ \\
$\mathbf{1 6}$ & $5.65 \pm 0.03^{\mathrm{aA}}$ & $3.92 \pm 0.05^{\mathrm{cA}}$ & $4.55 \pm 0.03^{\mathrm{bA}}$ & $3.05 \pm 0.03^{\mathrm{eA}}$ & $3.85 \pm 0.02^{\mathrm{dA}}$ \\
\hline
\end{tabular}

Means with the same small and capital letters in a raw and column were not significantly different at $\mathrm{P}<0.05$ level in various treatments.

Free Fatty Acids in fish oil develop undesirable flavors and harmful compounds. They also accelerate the degeneration and loss of product quality and increase of fat oxidation [24]. The results of FFA in different treatments of Hypophthalmichtys molitrix fish oil were shown in Table 3. The initial FFA value in all samples at first was $0.71-0.53$ oleic acid. According to the results, the amount of FFA in all treatments was increased with the passage of time and reached to 4.97, 3.23, 3.61, 2.83 and 2.96 oleic acid for control, $200 \mathrm{ppm}$ (Rosmarinus officinalis and Ocimum basilicum) and 800 ppm (Rosmarinus officinalis and Ocimum basilicum), respectively. Similar results were reported by Zolfaghari, shabanpour and falahzadeh [25] study. Although the amount of FFA was increased during storage, but this increase was not regular. The time, treatment and concentration had a significant effect on the formation of FFA during storage. The results showed that in the higher concentrations of Rosmarinus officinalis and Ocimum basilicum extracts, formation of FFA was less compared to the other treatments.

\begin{tabular}{|c|c|c|c|c|c|}
\hline \multirow{2}{*}{ Time(day) } & \multirow[t]{2}{*}{ control } & \multicolumn{2}{|l|}{200 ppm } & \multicolumn{2}{|l|}{800 ppm } \\
\hline & & $\begin{array}{l}\text { Rosmarinus } \\
\text { officinalis }\end{array}$ & $\begin{array}{l}\text { Ocimum } \\
\text { basilicum }\end{array}$ & $\begin{array}{l}\text { Rosmarinus } \\
\text { officinalis }\end{array}$ & $\begin{array}{l}\text { Ocimum } \\
\text { basilicum }\end{array}$ \\
\hline Zero & $0.71 \pm 0.03^{\mathrm{aE}}$ & $0.58 \pm 0.02^{\mathrm{cE}}$ & $0.67 \pm 0.04^{\mathrm{bE}}$ & $0.53 \pm 0.05^{\mathrm{dE}}$ & $0.59 \pm 0.03^{\mathrm{cE}}$ \\
\hline 4 & $1.81 \pm 0.02^{\mathrm{aD}}$ & $0.84 \pm 0.03^{\mathrm{dD}}$ & $1.09 \pm 0.03^{\mathrm{bD}}$ & $0.52 \pm 0.09^{\mathrm{eD}}$ & $0.95 \pm 0.04^{\mathrm{cD}}$ \\
\hline 8 & $3.01 \pm 0.01^{\mathrm{aC}}$ & $2.29 \pm 0.04^{\mathrm{cC}}$ & $2.52 \pm 0.09^{\mathrm{bC}}$ & $1.95 \pm 0.03^{\mathrm{dC}}$ & $2.08 \pm 0.03^{\mathrm{cC}}$ \\
\hline 12 & $4.12 \pm 0.03^{\mathrm{aB}}$ & $2.75 \pm 0.01^{\mathrm{cB}}$ & $2.83 \pm 0.03^{\mathrm{bB}}$ & $1.84 \pm 0.04^{\mathrm{dB}}$ & $1.93 \pm 0.05^{\mathrm{eB}}$ \\
\hline 16 & $4.97 \pm 0.02^{\mathrm{aA}}$ & $3.23 \pm 0.05^{\mathrm{cA}}$ & $3.61 \pm 0.04^{\mathrm{bA}}$ & $2.83 \pm 0.02^{\mathrm{eA}}$ & $2.96 \pm 0.04^{\mathrm{dA}}$ \\
\hline
\end{tabular}

Means with the same small and capital letters in a raw and column were not significantly different at $\mathrm{P}<0.05$ level in various treatments.

\section{CONCLUSION}

Sonication method preferred to solvent method because it saves time of extraction and is also more economic process and improves environmental, health and safe considerations. The comparison of Rosmarinus officinalis and Ocimum basilicum extracts indicated that Rosmarinus officinalis extract was slightly more efficient than Ocimum basilicum extract and it can delay chemical detoriaration in selective treatment rather control treatment. However, higher concentrations $(800 \mathrm{ppm})$ of both extracts were better than lower concentrations (200 ppm).
There is recommended that the UAM extraction of Rosmarinus officinalis and Ocimum basilicum are also used in other edible oils as alternative synthetic antioxidants

\section{REFERENCES}

[1] E. Desmond, Reducing salt: A challenge for the meat industry, Meat science 74(1) (2006) 188-196. https://doi.org/10.1016/j.meatsci.2006.04.014

[2] V.E. Kemi, M.U. Kärkkäinen, C.J. Lamberg-Allardt, High phosphorus intakes acutely and negatively affect $\mathrm{Ca}$ and bone metabolism in a dose-dependent manner in healthy young females, British journal of nutrition 96(03) (2006) 545-552.

[3] S. Mexis, E. Chouliara, M. Kontominas, Combined effect of an oxygen absorber and oregano essential oil on shelf life extension of rainbow trout fillets stored at 4 C, Food microbiology 26(6) (2009) 598-605. https://doi.org/10.1016/j.fm.2009.04.002

[4] K.I. Sallam, Antimicrobial and antioxidant effects of sodium acetate, sodium lactate, and sodium citrate in refrigerated sliced salmon, Food control 18(5) (2007) 566-575. https://doi.org/10.1016/j.foodcont.2006.02.002

[5] M.M. Cowan, Plant products as antimicrobial agents, Clinical microbiology reviews 12(4) (1999) 564-582.

[6] Y. Amakura, Y. Umino, S. Tsuji, H. Ito, T. Hatano, T. Yoshida, Y. Tonogai, Constituents and their antioxidative effects in eucalyptus leaf extract used as a natural food additive, Food Chemistry 77(1) (2002) 47-56.

https://doi.org/10.1016/S0308-8146(01)00321-1

[7] M. Asnaashari, R. Farhoosh, A. Sharif, Antioxidant activity of gallic acid and methyl gallate in triacylglycerols of Kilka fish oil and its oil-in-water emulsion, Food chemistry 159 (2014) 439-444. https://doi.org/10.1016/j.foodchem.2014.03.038

[8] M. Asnaashari, R. farhoosh, M. sharif, Evaluation of the methyl gallate effect on oxidation kinetic of purified kilka fish oil using sensitivity analysis based on artificial neural networks modeling, (2014).

[9] R. Farahmandfar, M. Asnaashari, R. Sayyad, Comparison antioxidant activity of Tarom Mahali rice bran extracted from different extraction methods and its effect on canola oil stabilization, Journal of Food Science and Technology (2015) 1-10. https://doi.org/10.1007/s13197-014-1702-2

[10] S. Khanzadi, S. Gharibzadeh, M.R. Raoufy, V. Razavilar, R. Khaksar, B. Radmehr, Application of artificial neural networks to predict clostridium botulinum growth as a function of Zataria multiflora essential oil, $\mathrm{pH}, \mathrm{NaCl}$ and temperature, Journal of food safety 30(2) (2010) 490-505. https://doi.org/10.1111/j.1745-4565.2010.00222.x

[11] M. Abdollahi, M. Rezaei, G. Farzi, A novel active bionanocomposite film incorporating rosemary essential oil and nanoclay into chitosan, Journal of Food Engineering 111(2) (2012) 343-350. https://doi.org/10.1016/j.jfoodeng.2012.02.012

[12] Y. Jiang, N. Wu, Y.-J. Fu, W. Wang, M. Luo, C.-J. Zhao, Y.-G. Zu, X.-L. Liu, Chemical composition and antimicrobial activity of the essential oil of Rosemary, Environmental Toxicology and Pharmacology 32(1) (2011) 63-68. https://doi.org/10.1016/j.etap.2011.03.011

[13] O. Politeo, M. Jukic, M. Milos, Chemical composition and antioxidant capacity of free volatile aglycones from basil (Ocimum basilicum L.) compared with its essential oil, Food Chemistry 101(1) (2007) 379-385. https://doi.org/10.1016/j.foodchem.2006.01.045

[14] P. Tongnuanchan, S. Benjakul, T. Prodpran, S. Pisuchpen, K. Osako, Mechanical, thermal and heat sealing properties of fish skin gelatin film containing palm oil and basil essential oil with different surfactants, Food Hydrocolloids 56 (2016) 93-107. https://doi.org/10.1016/j.foodhyd.2015.12.005

[15] M. Vinatoru, An overview of the ultrasonically assisted extraction of bioactive principles from herbs, Ultrasonics sonochemistry 8(3) (2001) 303-313. https://doi.org/10.1016/S1350-4177(01)00071-2

[16] D. Veličković, D. Milenović, M. Ristić, V. Veljković, Kinetics of ultrasonic extraction of extractive substances from garden (Salvia officinalis L.) and glutinous (Salvia glutinosa L.) sage, Ultrasonics sonochemistry 13(2) (2006) 150-156. 
https://doi.org/10.1016/j.ultsonch.2005.02.002

[17] A.C. Kimbaris, N.G. Siatis, C.S. Pappas, P.A. Tarantilis, D.J. Daferera, M.G. Polissiou, Quantitative analysis of garlic (Allium sativum) oil unsaturated acyclic components using FT-Raman spectroscopy, Food chemistry 94(2) (2006) 287-295. https://doi.org/10.1016/j.foodchem.2005.01.017

[18] S. Albu, E. Joyce, L. Paniwnyk, J. Lorimer, T. Mason, Potential for the use of ultrasound in the extraction of antioxidants from Rosmarinus officinalis for the food and pharmaceutical industry, Ultrasonics Sonochemistry 11(3) (2004) 261-265. https://doi.org/10.1016/j.ultsonch.2004.01.015

[19] R. Farahmandfar, M. Asnaashari, R. Sayyad, Comparison antioxidant activity of Tarom Mahali rice bran extracted from different extraction methods and its effect on canola oil stabilization, Journal of Food Science and Technology 52(10) (2015) 6385-6394. https://doi.org/10.1007/s13197-014-1702-2

[20] A.E. Goulas, M.G. Kontominas, Combined effect of light salting, modified atmosphere packaging and oregano essential oil on the shelf-life of sea bream (Sparus aurata): Biochemical and sensory attributes, Food chemistry 100(1) (2007) 287-296. https://doi.org/10.1016/j.foodchem.2005.09.045

[21] T. Misharina, A. Polshkov, Antioxidant properties of essential oils: autoxidation of essential oils from laurel and fennel and of their mixtures with essential oil from coriander, Applied Biochemistry and Microbiology 41(6) (2005) 610-618. https://doi.org/10.1007/s10438-005-0111-8

[22] S. Manju, L. Jose, T.S. Gopal, C. Ravishankar, K. Lalitha, Effects of sodium acetate dip treatment and vacuum-packaging on chemical, microbiological, textural and sensory changes of Pearlspot (Etroplus suratensis) during chill storage, Food chemistry 102(1) (2007) 27-35. https://doi.org/10.1016/j.foodchem.2006.04.037

[23] P. Lakshmanan, Fish spoilage and quality assessment, (2000).

[24] S.P. Aubourg, F. Pérez-Alonso, J.M. Gallardo, Studies on rancidity inhibition in frozen horse mackerel (Trachurus trachurus) by citric and ascorbic acids, European Journal of Lipid Science and Technology 106(4) (2004) 232-240. https://doi.org/10.1002/ejlt.200400937

[25] M. Zolfaghari, B. shabanpour, S. falahzadeh, Paper: Study of trend of chemical and microbial changes of rainbow trout (oncorhynchus mykiss) to determine the its optimum shelf-life during storage in refrigerator temperature (4 c), Iranian Journal of Natural Resource 64(2) (2011) 107-119. 